\title{
La representación de la clase obrera en la narrativa de Javier Pérez Andújar
}

\section{The Representation of the Working Class in Javier Pérez Andujar's Narrative}

Jesús Ángel Ruiz MoReno [jesusangelruiz@correo.ugr.es]

Universidad de Granada, España

\begin{abstract}
RESUMEN
Este artículo analizará el vínculo que existe entre el recurso a la autoficción en la narrativa de Javier Pérez Andújar y la representación que el autor hace de la clase obrera en el cinturón industrial de Barcelona y sus transformaciones históricas y políticas: por un lado, el paso histórico del trabajador meridional al inmigrante internacional y el del trabajo industrial al de sector servicios; por otro, la despolitización y derrota de la clase obrera desde finales de los 80. Para ello, se recurre al concepto "posición contradictoria de clase" desarrollada por Erik Olin Wright para explicar la problematización de la experiencia subjetiva del autor narrativo y la experiencia colectiva de la clase social.
\end{abstract}

\section{Palabras clave}

Pérez Andújar; representación de la clase trabajadora; autoficción

\begin{abstract}
This article analyzes the link between the use of autofiction in Javier Pérez Andujar's narrative and the representation of the working class, its historical and political transformations in the industrial belt of Barcelona. On the one hand, it shows the historical change of the working class, ranging from the worker from the South to the international immigrant and from the industrial worker to the service sector. On the other, the depoliticization and defeat of the working class from the 80s onwards. For that purpose, the article draws on the concept of "contradictory class location" developed by Erik Olin Wright, to explain the problematization of the subjective experience of the narrative author and the collective experience of the social class.
\end{abstract}

\section{KEYWORDS}

Pérez Andújar; representation of the working class; autofiction

RECIBIDO 2021-03-21; ACEPTADO 2021-06-09 


\section{Introducción}

Este artículo indaga en la representación de la clase obrera en la narrativa de Javier Pérez Andújar, es decir, en cómo la percibe, la define y construye sus transformaciones históricas desde tres perspectivas: la vinculada con el paso del tiempo y los cambios culturales aparejados (del franquismo a la actualidad); la de su conformación (del inmigrante de España meridional o charnego a los inmigrantes internacionales); la de la estructura del mercado de trabajo (del trabajador industrial al trabajador de servicios). Estas tres perspectivas, aclaramos, son las que operan en los textos de nuestro autor frente a otras articulaciones útiles para el análisis de las clases sociales, pero que no están presentes en los textos analizados.

Este artículo contribuye, esta sería su pertinencia, a la dilucidación de temas que han sido tratados en la literatura sobre nuestro autor, pero lateralmente o entrelazados con otras cuestiones: la articulación de la relación centro/periferia (García Ponce 2015) o la construcción urbana de Barcelona y su cinturón (Martínez Rubio 2016). Este, pues, será un análisis específico que puede arrojar luz sobre las tensiones ideológicas que atraviesan la narrativa y la crónica de Javier Pérez Andújar. Para eso, nos apoyaremos en el concepto de "posición contradictoria de clase" desarrollado por Erik Olin Wright (1994).

Hemos dividido nuestro artículo en cuatro apartados. En el primer apartado evaluamos los acercamientos críticos previos a la obra de Pérez Andújar respecto a la autoficción y la construcción social. A continuación, planteamos nuestra hipótesis de trabajo. En el tercer apartado, analizamos desde esta hipótesis la representación de la clase obrera en dos novelas -Los príncipes valientes (2007), Paseos con mi madre (2011) - y dos libros de crónicas -Milagro en Barcelona (2014), Diccionario enciclopédico de la vieja escuela (2016)- ${ }^{1}$. En el último apartado, extraemos las conclusiones que se derivan de los apartados anteriores.

\section{Interpretaciones sobre la función de la autoficción en la narrativa de Javier Pérez Andújar}

Toda la literatura sobre Javier Pérez Andújar ha abordado su narrativa desde el marco teórico de la autoficción. Aunque caben matices, tomamos la definición de García Ponce: una narración en primera persona en la que el narrador-personaje-autor trabaja la libre disposición de los materiales de su vida (2015: 23). ${ }^{2}$ Pérez Andújar no deja lugar a dudas acerca de que el material novelado es su propia vida: "Voy a decidirme por escribirme a mí mismo" (2007: 26); “[...] pero lo que he

1 Hemos excluido del análisis Catalanes todos y Todo lo que se llevó el diablo porque no se adecúan a los criterios de autoficción que, sin embargo, sí están presentes en los libros de crónicas citados. Hemos excluido, asimismo, La noche fenomenal (2019) debido a que, aunque pertenezca a la narrativa autoficcional, la representación de la clase obrera apenas cumple un papel residual.

2 La literatura sobre el concepto de autoficción es abundante y controvertida (Casas 2014; Pozo 2017): una discusión que clarificase el concepto impediría, por espacio, tratar adecuadamente nuestro objeto -la representación de la clase obrera en nuestro autor-. En todo caso, sí nos gustaría resaltar la vinculación que Manuel Alberca establece entre consenso neoliberal y autoficción. Según este autor el consenso neoliberal provoca una subjetividad sin señas de identidad y, por lo mismo, posibilita que cualquiera diseñe una identidad a su medida (2014: 152). Varios de los análisis sobre la obra de Pérez Andújar parten del criterio de la autoficción como búsqueda o elaboración de una identidad, aunque no la vinculen necesariamente al consenso neoliberal. 
tenido siempre claro es que no quería convertir mi experiencia -vamos, mi vida, que es mi material literario- en un discurso sociológico, sino en pura materia literaria" (Alonso y Gálvez 2016: 87). No obstante, las aproximaciones a su obra difieren en la interpretación del funcionamiento de la autoficción en su narrativa. Las podríamos dividir en dos tipos: aquellas según las cuales la autoficción contribuiría a la conformación de una identidad individual o colectiva y aquellas que imputan la autoficción a un malestar subjetivo que restañar.

Entre los primeros, García Conde (2015) sitúa la problemática de la narrativa de Pérez Andújar en la dialéctica centro/periferia. Esta problemática se bifurca en la denegación a los habitantes de la periferia el acceso al centro (Barcelona ciudad), por un lado, y la construcción de una identidad colectiva periférica (cinturón obrero), por otro. Para García Conde, como en cierto sentido para Martínez Rubio (2016), la problemática de Pérez Andújar es la construcción de una identidad propia de los habitantes del cinturón industrial de Barcelona. En términos parecidos, Mikel Aramburu habla de la "condición charnega" (2016: 147) que añadiría una distinción respecto a las culturas de origen de los migrantes. Los charnegos son ajenos a la sociedad de recepción, en este caso la catalana, en consonancia con la oposición centro/periferia; pero, al mismo tiempo, la condición charnega es extraña a sus raíces meridionales. Es decir, padecen un doble extrañamiento cultural, tanto de la cultura de origen como de la cultura de llegada.

Sin embargo, el intento de construir una identidad colectiva no explicaría por qué Pérez Andújar recurre a la autoficción como estructura narrativa y no a otras estructuras narrativas que se han usado para la construcción de estas identidades colectivas: por ejemplo, a la ciencia ficción a la que remite continuamente, en Los príncipes valientes, como a un elemento importante en su formación literaria. De hecho, en La noche fenomenal (2019), nuestro autor recurre, aun dentro de la autoficción, a la ciencia ficción. La última novela hasta ahora de Javier Pérez Andújar se distingue en múltiples aspectos de las que estamos analizando aquí. La razón más evidente es la comercial, dado que con La noche fenomenal nuestro autor ha pasado a publicar de Tusquets a Anagrama. Pero este cambio está acompañado del empleo de técnicas narrativas ajenas a Los príncipes valientes y Paseos con mi madre: el uso del diálogo en estilo directo, el paso de una narración en tiempos futuros a la narración en pretéritos, por señalar dos ejemplos significativos. No obstante, lo que cambia de forma drástica son los personajes que acompañan al narrador. ${ }^{3} \mathrm{Si}$ las anteriores eran novelas sobre la familia y la clase obrera de San Adrián del Besós, La noche fenomenal narra la vida de unos trabajadores de la cultura en Barcelona.

Dos autores han tratado de explicar la autoficción del autor catalán desde una lógica individual. Anna Caballé, antigua profesora de nuestro autor, nos remite a las aportaciones de la neurociencia y señala que el recurso a la autoficción se produce porque esta provoca una homeostasis que preserva la estabilidad emocional (2012: 29-30). Pero ¿cuál sería el desequilibrio que reparar mediante la autoficción en Pérez Andújar? Según Caballé, "una falta de acomodación” de carácter social (2012: 35). Esta expresión, quizá un tanto ambigua, desemboca en el conflicto centro/periferia, el charnego o el obrero, pero vivido de una manera no colectiva, sino subjetiva. Por su parte, Martínez Rubio insiste en que la escritura autobiográfica tiene "un efecto sanador en la subjetividad del autor" (2015a: 117), es decir, terapéutico; aunque adjudica esta necesidad de restaurar el equilibrio perdido a la búsqueda de la reconciliación con su memoria y su familia. 
Más allá de la terapéutica emocional, lo que nos importa discutir es si el desequilibrio -la contradicción- que atraviesa la literatura de Pérez Andújar radica en esa búsqueda de acomodación social o de reconciliación con la memoria y la familia. En ese sentido, nos parecen más atinadas las reflexiones, aunque recogidas de forma muy lateral, de García Conde. Este intuye que la escritura de Pérez Andújar está, al mismo tiempo, cercana y lejana a lo que narra. Unas veces -señala- participa en la acción, mientras que otras se manifiesta distante e irónico; además, si bien en ocasiones se declara uno más de la clase obrera, en otras se presenta como ajeno a ella (2015: 117). El siguiente fragmento de Los príncipes valientes resume perfectamente esta contradicción, que nosotros analizaremos en el próximo apartado:

Me fascinará en mi pertenencia a la masa obrera el ideal del pueblo unido, pero a la vez rechazaré este idealismo, afectado de una aristocracia literaria que me ha sobrevenido tardíamente, y poseído por un biográfico resentimiento contra la clase en la que nací, producto de mi incapacidad para integrarme en ella. En esta marginación que ya no distingo si fue voluntaria o accidental, voy a exaltar vehementemente al solitario que corre, al Pinocho de madera cuando quiere huir de su condición artesanal, y voy a aclamar a los detectives vestidos de hombres vulgares que corren como personajes de cuentos entre gigantes de cemento. Pero todavía por encima de la épica del hombre que corre escapando de ella, me sentiré fascinado en mi exclusión por la figura marginal del teniente Colombo, que es un individuo hijo de la masa, que se aparta discretamente a un lado para anotarlo todo en su libreta de hombre que escribe, y este al que yo voy a querer imitar en todo momento.

(2007: 229-230)

\section{Posición contradictoria de clase}

The Uses of Literacy. Aspects of Working-Class Life de Richard Hoggart [1957], traducida al español como La cultura obrera en las sociedades de masas, es posiblemente el clásico que inaugura el estudio etnográfico de la clase trabajadora. A pesar de esta marcada diferencia de género y contexto histórico, la obra de Hoggart mantiene características comunes con la obra de Pérez Andújar: los dos autores comparten el origen obrero, la importancia de las relaciones familiares en la composición de sus textos, así como la reflexión sobre la influencia de los medios de comunicación de masas en la clase obrera. Pero el elemento, para nosotros, que los vincula extraordinariamente es la posición de Hoggart y Pérez Andújar respecto a su clase de origen y a su origen de clase. Hoggart afirma: "I am from the working-classes and feel even now both close to them and apart from them" (2009: 7). ${ }^{4}$ La sentencia del autor inglés se compadece perfectamente con las afirmaciones del narrador en las obras del autor catalán: "Esa gente son los míos. Pertenezco a una clase por encima de cualquier otra pertenencia" (2016: 149); "De chaval voy a sentirme ciudadano del mundo desde el pasillo ancho y luminoso de mi escalera de vecinos; pero ahora lejos de mis bloques, sin haber sido capaz de pertenecer a ellos, me siento profundamente apátrida" (2011: 153).

4 "Provengo de las clases trabajadoras y me siento, incluso ahora, tanto perteneciente a ellas como fuera de ellas" (la traducción es nuestra). 
Estas dos posturas simultáneas, como señalaba García Conde (2015), que atraviesan toda la obra de Pérez Andújar conforman la tensión que sostiene la estructura autoficcional de su escritura. Para explicar correctamente este dentro y fuera simultáneo que comparten Hoggart y Pérez Andújar, hemos recurrido al concepto de "posiciones contradictorias de clase" de Erik Olin Wright (1994: 48-68). Wright utiliza este concepto para toda una serie de posiciones de clase que se han definido como clase media, nueva pequeña burguesía o ejecutivos. Una de ellas es la definida por Wright como "posición de clase semiautónoma" (1994: 54-55) que tendría tres especificaciones: 1) control sobre el propio proceso de trabajo, 2) control sobre los medios físicos de producción (Pérez Andújar considera el lenguaje su medio de producción) ${ }^{5}$ y 3) un mínimo control sobre cómo se produce. Las tres características son imposibles de trasladar al trabajador industrial de Los príncipes valientes ni a los trabajadores industriales o de servicios de Paseos con mi madre. En esta última, se perfila esta diferencia de clase, entre otros ejemplos, en la lengua empleada y la vestimenta: "Y así se quedarán ambas lenguas, durante años separadas no por ser idiomas distintos sino por la distinción sociológica que hay entre sus hablantes. En Barcelona, ser catalán consiste más en pertenecer a un estatus social que en pertenecer a un país [...] Me dará vergüenza ser catalán como me va a dar vergüenza ponerme corbata. Eso son cosas que no se hacían en mi casa" (2011: 105-106). La corbata, símbolo habitual de los trabajadores de cuello blanco, no solo era inhabitual en el hogar familiar de la familia Pérez Andújar, sino que, siguiendo la expresión, era algo que parecía hasta prohibido o, al menos, mal visto socialmente.

La "explotación" de las palabras lo extraerá de la clase social de origen, a la que no pertenece por oficio. Por supuesto, no ha pasado a formar parte de los capitalistas, pero sí ocupa una posición contradictoria que le permite controlar su proceso de trabajo, si bien es cierto que carece de dominio en el proceso de trabajo ajeno ni en el de mercantilización (la edición y comercialización de su trabajo). Las consecuencias de esta distinción quedan recogidas en este revelador fragmento:

Y cuando me dé por preguntarme si, ya que no tengo un sentido de pertenencia geográfica o nacional, por lo menos habré sabido mantener una pizca de la ideología política que fluía en nuestra casa, descubriré que el socialismo materialista de mi padre, de revisión salarial anual y de horas extraordinarias retribuibles, y su internacionalismo de trabajadores de la fábricas del mundo, los he ido transformando en un internacionalismo de leer revistas extranjeras en el sofá, y un socialismo de lecturas utópicas a lo conde de Saint-Simon, y a lo Cabet, y a lo Williams Morris, y a lo H. G. Wells, y que es un socialismo de vida más solucionada y de vida al aire libre, y en el colmo de mi inclinación por la vida muelle acabaré convirtiéndolo en un socialismo abstracto de asociacionismo de palabras, aunque al final va a resultar que todavía hay clases, será un asociacionismo modesto y popular, propio de una asociación de vecinos. (Los príncipes valientes 2007: 103-104)

Si nuestra hipótesis es cierta, las referencias a las identidades periféricas, al charnego, al extrarradio de Barcelona, a la separación del centro por el río Besós encuentran su sentido a partir del análisis de esta posición contradictoria de clase antes que en otras claves. No es una reconciliación con un mundo en el que no termina de encontrar acomodo o con la historia familiar, sino fruto

5 "Las palabras crean realidad, pero esta no les pertenece igual que el obrero crea riqueza sin formar parte de ella. El lenguaje es la clase obrera de la realidad, es la mano de obra que la construye. A cada palabra que se dice o que se escribe, la realidad le debe una cuota de plusvalía" (2011: 148-149) 
de la tensión entre su pertenencia histórica a la clase obrera y su posición contradictoria actual. Por eso mismo, cómo representa la clase obrera y sus transformaciones es determinante en su literatura. Sin embargo, no debemos dejar de señalar que la propia estetización de la clase obrera que se da en los cuatro textos que analizamos comporta la pérdida de su horizonte revolucionario y su conversión en objeto de consumo.

\section{Tres generaciones superpuestas}

García Ponce señala que la narrativa de Pérez Andújar describe la vida de tres generaciones de trabajadores. La primera la formaría la migración interna durante el franquismo (la familia de Pérez Andújar proviene de Gor, provincia de Granada); la segunda, la de las luchas bajo el tardofranquismo y la transición (derechos laborales y la democracia); la tercera, la clase obrera actual (García Ponce 2015: 21). Estamos parcialmente de acuerdo con este autor, a pesar de dos riesgos de confusión.

El primer riesgo, en el que no incurre García Ponce, sería creer en una clase obrera identitaria (por origen, los charnegos, o por disposición espacial, los habitantes de las periferias). En Pérez Andújar, la clase obrera, como veremos, se conforma en oleadas y mutaciones sucesivas. El segundo peligro es la sucesión temporal de las generaciones. En este caso, estimamos que, por ejemplo, la sucesión entre la primera y la segunda generación no es tal, sino que son simultáneas: el arribo y conversión de trabajadores del campo en trabajadores industriales es simultánea a su politización. No obstante, como incidiremos en el punto 3.1, sí se mantienen dos formas culturales: la cultura oral de los trabajadores del campo frente a la cultura visual y politizada del trabajador industrial. Del mismo modo, en la tercera generación conviven las oleadas de migrantes extranjeros que modifican el paisaje con el decaimiento del trabajador industrial. Además, el paso del trabajo industrial al trabajo en el sector servicios modificará la conciencia, también la conciencia política, de la clase trabajadora (punto 3.3).

\subsection{Los príncipes valientes: el pícaro y el sindicalista}

Los príncipes valientes (2007) narra la infancia de Pérez Andújar: sus primeros acercamientos a la lectura y la cultura de masas y la relación que mantiene con Ruiz de Hita, un compañero de clase, lector como él. La exigua trama de la novela se explica al final. Descubrimos que Ruiz de Hita es hijo de guardia civil, algo que causaba terror en la familia de narrador. La familia temía que, por medio de Ruiz de Hita, la guardia civil descubriese las actividades sindicales clandestinas del padre. Mientras se describe la conformación de una serie de gustos culturales -que abarcan desde Manrique a los tebeos o las series de televisión (le dedica más de 20 páginas a Colombo)-, se deslindan dos formas culturales de las clases populares en el extrarradio de Barcelona: la del obrero industrial y la del trabajador del campo:

El campo es más literario que la fábrica, el analfabetismo del campo tiene más palabras, más vocabulario, que el analfabetismo de la industria, porque en el campo hay una tradición oral, una litera- 
tura popular, que no se da en las cadenas de montaje y en los grupos de viviendas. Es la diferencia de clase o el cisma de clase que va a abrirse como una cárcava entre cultura oral y cultura visual. (2007: 55)

Esta ruptura entre formas de la clase trabajadora, esta cárcava según nuestro autor, se ancla en las diferencias entre dos personajes: el padre del narrador y el tío Ginés, hermano de la madre. El tío Ginés representa la vida del campesino pobre en el extrarradio barcelonés: “También voy a pretender ser o haber sido un hombre de campo como mi abuelo lo fue, o como lo es mi tío incluso en Barcelona" (2007: 55). Este campesino "incluso en Barcelona” asume todas las características del pícaro: "Antes que trabajador del sector de la química catalana, mi tío ha sido un pícaro andaluz, cuyo único objetivo diario consistirá en encontrar algo con lo que acallar el estómago" (2007: 42). ${ }^{6}$

La cultura popular heredada del campo, que aparece también en los relatos que hace la madre sobre la vida del abuelo y del pueblo, es uno de los elementos centrales de la construcción estilística de nuestro autor. Como se ha señalado (Martínez Rubio 2015a; Cáliz 2015), la escritura de Pérez Andújar podría definirse como "neobarroca”, estilo literario en el que proyecta la memoria de su familia materna: su tío Ginés le hablará "en su arcaico castellano de los siglos de oro" (2007: 57). El narrador comparte con su tío Ginés paseos por el campo, la recolección de anécdotas y pillerías del campo granadino y la pasión por la literatura popular y fantástica: "De la mano de mi tío Ginés voy a adentrarme en una literatura fantástica y popular a la que no llegaré a través de los cuentos y ejemplos sin moraleja que mi madre me relata en la cocina" (2007: 201). Esta literatura popular, este analfabetismo rico en palabras se condensa en Lazarillo de Tormes ${ }^{7}$ :

La picaresca española es un muchacho ejerciendo su derecho a las cosas en un mundo en el que se le han negado todos los derechos. En mi tío, claro, hay mucho de un Lazarillo de Tormes al que un país de ciegos le está golpeando la cabeza contra un toro de piedra (acaso, porque Jorge Manrique dijo que nuestras vidas son los ríos, el Lazarillo quiso nacer en una aceña, a las orillas del río, y llevar como apellido el nombre de ese río). La picaresca es la epopeya, la poesía heroica del pobre, y por eso el Lazarillo se parece tanto al Cid en su andar buscando un buen señor a quien servir. (2007: 42- 43) ${ }^{8}$

Frente a esta libertad pícara, habladora, del tío Ginés, en Los príncipes valientes aparece la libertad silenciosa del trabajador industrial representado por el padre del narrador: "Mi padre y sus

6 Quizá sea necesario distinguir el pícaro de nuestro autor de otros modelos, por ejemplo, Manolo, “el Pijoaparte”, el protagonista de Últimas tardes con Teresa (1966), de Juan Marsé. El tío Ginés, como Lázaro, se conforma con un mínimo de bienestar vital, no hay deseos de movilidad social, solo de saciar el hambre; por su parte, el Pijoaparte encarna una "una feroz lucha por escapar de la miseria y ascender socialmente" (Bellón 2009: 29). El tío Ginés sería a Lázaro lo que el Buscón al Pijoaparte.

7 La recurrencia a Lazarillo de Tormes tiene mucha relevancia en otros aspectos como en la alegoría del río Besós (río que separa Sant Adrián del Besós de Barcelona, extrarradio de la capital).

8 La interpretación de la obra picaresca anónima que hace Pérez Andújar plantea un espejismo sobre quién narra en la novela picaresca. Por supuesto, es imposible que el sujeto pobre tomara directamente la palabra en el siglo XVI, sino que es un artificio de la burguesía emergente que solo puede romper con el constreñimiento impuesto por el feudalismo trasladando su voz al pobre sin amo. La diferencia con el Cid es tajante: el Cid sí tiene señor, independientemente de su bondad, pero Lázaro es un mozo de muchos amos que carece de ese señor natural. Esa es la diferencia mediante la cual se introduce el discurso de la burguesía emergente. Véase la obra de Juan Carlos Rodríguez (1994: 111-145). 
amigos al silencio litúrgico del franquismo le han opuesto su silencio proletario, que es un silencio de resistir y no cantar" (2007: 38). Este silencio es político, silencio que simboliza la resistencia a las torturas de la policía franquista; pero es, al mismo tiempo, fuerza de trabajo en acción: "El que yo aprendí fue un silencio metalúrgico, chispeante como el brillo de las soldaduras. ¿Por qué no se celebrará también el día internacional de la lengua paterna juntando todo el silencio de todas las fábricas del mundo?” (2014: 9).

La distinción entre ambos modelos de trabajadores no se limita al ámbito cultural en el que se manejan. Hay una segunda diferencia que se puede comprobar en la equiparación con la naturaleza del trabajador industrial. En una escena de intensísimo lirismo de Los príncipes valientes el narrador, bajo la lluvia, espera el regreso de su padre en el autobús de la fábrica; las reflexiones del autor, mientras aguarda, asimilan al padre con la naturaleza: "Otras veces la lluvia se va antes de que llegue el autocar, por compañerismo, o por compromiso de clase, y lo que queda en la calle es el vacío de un día de lluvia sin lluvia” (2007: 20). Si el tío Ginés es el relato popular y el pícaro barroco, el obrero industrial es el silencio y el trabajo equiparado a las fuerzas de la naturaleza. Este vínculo es idéntico al que Marx hace en Crítica del programa de Gotha [1891]; mientras que el campesino emigrado solo busca "acallar el estómago", el obrero industrial es el silencio de la fábrica, en cuanto intermediario entre la naturaleza y los valores de uso -es decir, trabajo-, y es, en cuanto fuerza de trabajo, una fuerza natural como la lluvia. ${ }^{9}$

Todavía una tercera diferencia forma esta cárcava entre el campesino en la ciudad y el obrero industrial: la lucha sindical y política. Pérez Andújar sorprende de niño a su padre en reuniones clandestinas, espera en casa durante encierros en iglesias por la readmisión de trabajadores despedidos, comparte piquetes en huelgas generales. Esta lucha política requiere otro canal de expresión que es la palabra escrita. Los relatos orales del tío Ginés y la madre se tornan en la palabra escrita de la octavilla sindical:

Voy a aprender en las octavillas de esos días a llamar al trabajo por su nombre propio, o por sus nombres propios. El trabajo, ante todo, es en mi casa el nombre de la fábrica de la que viene y a la que va mi padre; pero es además el nombre de todas las fábricas de Barcelona, y de toda España en un sindicalismo de hombres que han decidido levantarse y cambiar las cosas, de una manera que nunca hasta entonces se habían imaginado que podían atreverse. Cada ola de la historia trae su espuma de valor, y en el fervor de eso días veo a obreros como mi padre, con el alfabeto precario de las cuatro letras y de la regla de tres, pertrechados de escritos que reparten furtivamente, y de ellos aprendo que las palabras son lo primero que uno tiene, y lo que más dura, y también lo que uno más necesita. (2007: 176)

9 "La naturaleza es la fuente de los valores de uso (¡que son los que verdaderamente integran la riqueza material!), ni más ni menos que el trabajo, que no es más que la manifestación de una fuerza natural, de la fuerza de trabajo del hombre”. (Marx 1975: 10). Como vemos, en la cita de Marx se da también esta doble condición: el trabajo es el intermediario, transforma, la naturaleza en valores de uso (ese es el silencio de la fábrica en nuestro autor) y, al mismo tiempo, es parte de la naturaleza en cuanto fuerza de trabajo. 


\subsection{La democracia es fruto del trabajo}

Esta clase obrera politizada y luchadora que representa el silencio, la fuerza de trabajo y la escritura son, para nuestro autor, los hacedores de la democracia:

La democracia la fueron conquistando estos hombres y mujeres calle por calle, árbol por árbol. La democracia es una cosa que se puede tocar, y que esta gente tuvo en sus manos durante días seguidos y noches enteras. Conseguir un colegio público en un barrio que no lo tenía; la construcción de un ambulatorio donde no llegaban los médicos; dejar una plaza sin edificar para que los niños jueguen; hacer un polideportivo para que el único deporte no sea apedrear perros; lograr que pase el autobús por donde no pasaba nada o que llegue el metro a donde no llegaba para poder ir al trabajo sin necesidad de pisar charcos, sin aguantar la lluvia y el frío de la madrugada, sin andar por los descampados que separaban el barrio de los transportes públicos, esa es la democracia que hicieron realidad estas gentes encerrándose en los locales de las asociaciones de vecinos, encadenándose a verjas, cortando el tráfico, protestando en la calle, luchando. La democracia es algo que se ve y se toca, y donde no se percibe es que no la hay. La democracia es ante todo una cosa de manobras porque en última instancia se hace con las manos. (2011:58)

Aunque el Diccionario de la Real Academia Española no recoge el término "manobra", sino "manobre". No cabe duda de que su significado se vincula al trabajo más descualificado (manobre es el peón, el que ayuda al oficial) y a su formación (mano y obrar). Así, nuestro autor erige la imagen de una democracia fruto del trabajo que difiere de la imagen celebrada y común de la transición española y, en consecuencia, del tan traído y llevado "desencanto" (Martínez 2017). Cuando Pérez Andújar escriba sobre El desencanto de Jaime Chávarri ${ }^{10}$, convertido en tema recurrente para el análisis de la cultura española en la monarquía parlamentaria (Vilarós 2018), mantendrá esa concepción de la democracia como fruto de la lucha de la clase trabajadora. Esta concepción se enfrenta a la visión del desencanto intelectual que segrega la película sobre la familia Panero:

Pero el desencanto fue un gesto de dandismo, una mueca de cansancio. Las gentes que retrataba Guerrero en aquellos años de aventura, en los descampados de las afueras, en las manifestaciones vecinales de los bloques, no eran los que se desilusionaron de la democracia. El hastío es un artículo de lujo. La gente pobre no se cansa de las cosas, solo se harta quien ya tiene. Se forjó el desencanto igual que la democracia, de arriba abajo. (2014: 13)

Si comparamos el discurso dominante en el documental sobre los Panero con el texto de Pérez Andújar, comprobamos cómo la misma posición contradictoria de clase que implica la dedicación profesional a la escritura se ve afectada por las distintas trayectorias en la dinámica de clases. La

10 El desencanto es un documental de Jaime Chávarri de 1976. La película realiza una retrospectiva sobre el poeta Leopoldo Panero a través de su viuda y sus hijos (asimismo poetas). Aunque pareciera que el documental muestra cómo se deshacen los cimientos sociológicos del régimen franquista y la apertura a la democracia, desde muy pronto ha sido interpretada como ejemplo paradigmático de la desafección de los intelectuales con la Transición y la institucionalidad naciente. La ácida crítica de nuestro autor recalca el olvido que esta interpretación hace de aquellos que lucharon contra el franquismo y produjeron, para seguir con su metáfora, la democracia. 
familia acomodada que manifiesta su cansancio la confronta nuestro autor a los trabajadores para quienes el hastío es un lujo y la democracia, la victoria tras un largo combate; victoria provisional e inestable, como veremos.

\subsection{Paseos con mi madre: las tres chimeneas, Pryca y los trabajadores inmigrantes}

Paseos con mi madre distingue la clase obrera en dos momentos históricos en una narración plagada de saltos temporales. El primero, narra la lucha por la democracia, que ya aparecía en Los príncipes valientes; el segundo contiene dos transformaciones de la clase obrera en el cinturón barcelonés: su internacionalización y la conversión del trabajador industrial en trabajador de servicios.

La internacionalización de la clase obrera se describe a través de los cambios de la Feria de Abril de Barcelona. Aunque Mikel Aramburu impute los desajustes de la descripción a la identidad no meridional del charnego (2016: 140), la Feria de Abril fue la fiesta mediante la que los charnegos remedaban las formas culturales del Sur en la Barcelona que los excluía. Esto no obsta para que esta fuera una fiesta sensiblemente distinta de la sevillana que imita. La clave no es que los charnegos no escuchen rumba o sevillanas, no es que les resulten completamente ajenas, sino que los que acuden en la segunda década del siglo XXI a la Feria de Abril no son ya charnegos. Los que acuden forman una clase obrera internacionalizada. En la segunda década del siglo XXI buscan su ocio en ella "Latin Kings con sus gorras de lado, mujeres con velo y cochecitos de bebé, mestizos de nariz de cóndor, niños de Bangladesh vendiendo rosas a precio de Banco Mundial [...]” (2011: 35). Y prosigue: "Los multiculturales son los que pasean aburridos por la feria, no los que la organizan. Para ser multicultural basta con ser pobre, porque cada pobre lo es a su manera”. (2011: 35). Como acertadamente señala García Ponce (2015), no hay nostalgia en el retrato de estas transformaciones; al contrario, en la misma dinámica de cercanía y lejanía que defendemos afirma nuestro autor: "Antes que sentirme de ningún país, de ninguna patria o nación, voy a pertenecer a la internacional de los bloques" (2011: 107).

Más compleja es la relación con el paso de la clase obrera industrial a la del sector servicios. El capítulo 10 de Paseos con mi madre, "El color que cayó del cielo", ahonda en la construcción de un Pryca en la zona de San Adrián del Besós, mientras que el capítulo 13 rememora una huelga de 1973 en la que la policía asesinó a Manuel Fernández Márquez.

Como vemos, en la novela se narra antes el declive económico de la zona que la huelga del 73. Nosotros seguiremos en nuestro análisis un criterio cronológico. El capítulo 13, "Huelga en las tres chimeneas", se detiene en uno de esos momentos que, veíamos en el apartado anterior, trajeron la democracia. Los trabajadores de la térmica ${ }^{11}$ inician una huelga en la que reivindican la jornada de ocho horas y otros derechos laborales afines. En una asamblea los trabajadores decidieron ocupar los puestos de trabajo ante la oposición de la dirección de la empresa. Durante el intento de ocupación la policía cargó contra los trabajadores asesinando a Manuel Fernández Vázquez: "Yacía sobre un charco de sangre muerto por una bala que le había atravesado la cabeza” (2011: 141).

11 La térmica, conocida en la zona popularmente como "tres chimeneas" fue una central de energía eléctrica de tres plantas fundamental en los años 70. En la actualidad, como veremos enseguida, se encuentra cerrada y en desuso. 
De distinta manera escenifica a la clase obrera que, pasado el tiempo, solo encuentra trabajo en el sector servicios -el mismo Pérez Andújar trabajó en la sección de panadería de Pryca-. Si los trabajadores industriales trataron de ocupar la térmica, los trabajadores del centro comercial no encuentran espacios de lucha:

A todos los que va echando el Pryca les cuentan lo mismo en el sindicato: que no hay nada que hacer. Los sindicatos no se juntan con desconocidos, no quieren tener nada con los trabajadores sin afiliar. Solo se escuchan a sí mismos. Tienen miedo, como todo el mundo. Miedo de todo. (2011: 114-115)

Las consecuencias no son simplemente el empeoramiento de las condiciones laborales o los contratos basura o la acumulación de despidos improcedentes. ${ }^{12}$ La consecuencia es la suspensión de la democracia. Como se comprueba en la reflexión que concluye el capítulo 13 de Paesos con mi madre; esta aúna el fin del trabajo industrial y la caída de la combatividad de la clase obrera con el fin de la democracia

Hoy las tres chimeneas de la térmica se han cerrado porque su trabajo ya no es necesario. Pero continúan siendo algo extraño que se ve desde lo lejos. Ahora el ayuntamiento de San Adrián no sabe bien qué hacer con ellas, si derribarlas o convertirlas en hoteles o en museos. Convocó un referéndum para preguntar a los vecinos qué les parecía mejor, y no fue nadie a votar. (2011: 145-146)

\section{Conclusiones}

Como hemos analizado, la clase obrera ocupa un lugar central en la obra de Javier Pérez Andújar. La clase obrera se representa, por un lado, única, puesto que lo que la distingue es la pobreza. Carece de otros rasgos identitarios positivos "porque cada pobre lo es a su manera" (2011: 35). Así, la dinámica de la historia implica distintas conformaciones: laborales, culturales, lingüísticas o nacionales. La clase obrera es al mismo tiempo el campesino emigrado que no ha terminado de adaptarse a la vida urbana, el trabajador industrial que lucha por la democracia, el hijo de esa clase que, toda vez cerrada la actividad industrial, padece los estragos del trabajo en las grandes empresas de distribución y comercio, las olas de inmigrantes que, como los meridionales españoles que arribaron durante el franquismo, han llegado al cinturón de Barcelona de todos los lugares del mundo.

En definitiva, la clase obrera no queda limitada a la clase obrera industrial. Sin embargo, por otro lado, los trabajadores de la industria desempeñan una función privilegiada en la consecución de la democracia, como hemos visto en las metáforas utilizadas: "Porque la democracia viene del trabajo, y la prueba es que ahora que falta trabajo escasea la democracia. La democracia no fue una aparición celestial. Hubo que hacerla como el alfarero hace una jarra. La democracia es crear, construir" (2016: 149). Ni el campesino emigrado, representado por el tío Ginés, ni la clase

12 Este capítulo narra también el proceso de proletarización del pequeño comerciante. Los comerciantes llegan a un acuerdo con la dirección del centro comercial para que contrate a sus hijos: "Lo que va a hacer la clase media del barrio es entregar a sus primogénitos. Y el que no tenga primogénito se sacrificará a sí mismo” (2011: 110) 
obrera del sector servicios, tampoco la clase obrera inmigrante poseen esa fuerza en sus novelas. Por otra parte, del campesino que no termina de desprenderse de su cultura oral y arcaica toma el autor una forma de cultura popular que lo entronca con la literatura barroca, especialmente, con la literatura picaresca.

Esta compleja y variable simbolización de la clase obrera y, especialmente, el uso de la autoficción como andamiaje de la narración las hemos explicado a partir del cambio de posición social del autor. Según la terminología de Erik Olin Wright, hemos definido este cambio como posición contradictoria de clase. Esta caracterización implica que la autoficción no es efecto, estrictamente, de la falta de acomodo social. En La noche fenomenal, última novela del autor hasta el momento, no se percibe esta sensación de falta de acomodo cuando narra las peripecias de un grupo de trabajadores de la cultura en Barcelona ${ }^{13}$. Tampoco la autoficción se explica por el intento de reconciliación con la familia y la memoria. Por el contrario, la autoficción, en estas novelas y crónicas de Javier Pérez Andújar, es la vía mediante la que esta posición contradictoria puede saturarse y mostrarse. La autoficción permite al autor incluirse y excluirse simultáneamente de la clase obrera sin que la narración resulte autorrefutativa. La autoficción es, en conclusión, la forma en que la contradicción subjetiva se torna productiva.

\section{Referencias bibliográficas}

Alberca, M. (2014). De la autoficción a la antificción. Una reflexión sobre la autobiografía española actual. In Casas (ed.), El yo fabulado: nuevas aproximaciones críticas a la autoficción (pp. 149-169). Madrid: Editorial Iberoamericana.

Alonso Alemany, R.; \& Gálvez Roca, O. (2016). Una tarde con Javier Pérez Andújar. Cuadernos Hispanoamericanos, 787, 86-97.

Aramburu, M. (2016). ¿Vindicando al charnego? El discurso autobiográfico de Javier Pérez Andújar y Jorge Javier Vázquez. Revista de dialectología y tradiciones populares, LXXI, 1, 129-149.

Bellón Aguilera, J. L. (2009). La mirada pijoapartesca (Lecturas de Marsé). Ostrava: Ostravská univerzita v Ostravě.

Caballé, A. (2012). Malestar y autobiografía. Círculo de Lingüística Aplicada a la Comunicación, 50, 25-38.

Cáliz Montes, J. (2015). Modos subordinados de acceso a los clásicos en Los príncipes valientes de Javier Pérez Andújar. Amnis, 14. https://doi.org/10.4000/amnis.2586

Casas, A. (2014). La autoficción en los estudios hispánicos: perspectivas actuales. In A. Casas (Ed.), El yo fabulado: nuevas aproximaciones críticas a la autoficción (pp. 7-21). Madrid: Editorial Iberoamericana.

García Ponce, D. (2015). Periferias urbanas: retrato del extrarradio barcelonés en las novelas de Javier Pérez Andújar. Ángulo Recto. Revista de estudios sobre la ciudad como espacio plural, 7, 2, 19-33.

Hoggart, R. (2009) [1957]. The uses of literacy. Aspects of working-class life. London: Penguin.

Martínez Rubio, J. (2015a). Neobarroco popular. Humor, autobiografía y lenguaje en la obra narrativa de Javier Pérez Andújar. Confluenze, 7, 2, 107-119.

13 Ya hemos visto que, aunque en La noche fenomenal persiste el relato autoficcional, hay suficientes cambios técnicos para distinguirla de Los príncipes valientes y Paseos con mi madre. 
. (2015b). "Por definición si ganas, es que eres malo. Lo bueno es perder”. Diálogos sobre la derrota con Javier Pérez Andújar. Confluenze, 7, 2, 140-147.

- (2016). Cuarenta años de paz y cuarenta de aluminosis. Territorio, memoria e identidades periféricas en Paseos con mi madre de Javier Pérez Andújar. Artifara, 16, 335-346.

- (2017). El discreto desencanto de la burguesía o contra la crítica oficial de la Transición: Cercas, Reig y Pérez Andújar. Dicenda. Cuadernos de Filología Hispánica, 35, 227-245.

Marx, K. (1975) [1891]. Crítica al programa de Gotha. In K. Marx, \& F. Engels, Obras escogidas (vol 2) (pp. 10-42). Madrid: Akal.

Pérez Andújar, J. (2007). Los príncipes valientes. Barcelona: Tusquets.

- (2011). Paseos con mi madre, Barcelona: Tusquets.

- (2014). Milagro en Barcelona. Barcelona: Ariel (versión digital).

- (2016). Diccionario enciclopédico de la vieja escuela. Barcelona: Tusquets.

- (2019). La noche fenomenal. Barcelona: Anagrama.

Pozo García, A. (2017). Autoficción en la novela: realidad, ficción y autobiografía. Impossibilia. Revista Internacional de Estudios Literarios, 13, 1-20.

Rodríguez Gómez, J. C. (1994). La literatura del pobre. Granada: Comares.

Vilarós, T. M. (2018). El mono del desencanto: Una crítica cultural de la transición española (1973-1993). Madrid: Siglo XXI.

Wright, E. O. (1994). Clases. Madrid: Siglo XXI. 
